Documentación de las Ciencias de la Información ISSN: 0210-4210

http://dx.doi.org/10.5209/DCIN.57670

\title{
El establecimiento fotográfico y la revista Instantáneas de los hermanos Salvi Loscos. Documentación sobre el comercio, la industria y los modelos comunicativos en fotografía
}

\author{
Juan Miguel Sánchez-Vigil ${ }^{1}$, María Olivera Zaldua²
}

Recibido: 12 de mayo de 2015 / Aceptado: 15 de junio de 2017

Resumen. En la historia de la fotografía española las investigaciones sobre la industria y específicamente sobre el comercio y su función sociocultural son muy escasas, así como sobre los profesionales que pusieron en marcha este tipo de negocios. La familia Salvi fue una de las más emprendedoras, con varias empresas desde finales del siglo XIX hasta la Guerra Civil de 1936. Se da a conocer en este trabajo la actividad profesional e intelectual de los Salvi a través del establecimiento fotográfico fundado y dirigido por Carlos Salvi Loscos en 1887, y de la revista Instantáneas, creada y dirigida por su hermano Manuel Salvi Loscos en 1898. Se aportan datos inéditos para la historia de la fotografía española en una doble vertiente: por una parte, el impacto social y cultural del comercio en la actividad fotográfica, y por otra la función e interés de la revista Instantáneas, entre las especializadas en la materia, a partir del análisis de sus contenidos.

Palabras clave: Fotografía; Historia de la Fotografía; Comercios de fotografía; Industria de la fotografía; Carlos Salvi Loscos; Manuel Salvi Loscos; revista Instantáneas.

\section{[en] The Photo Store and the Instantáneas magazine of the Salvi Loscos Brothers}

\begin{abstract}
About the history of Spanish photography, there have been very few investigations carried out on the industry in general and specifically on the photography stores and their socio-cultural function, as well as on the professionals who launched this type of business. The Salvi family was one of the most enterprising and they managed several companies from the end of the $19^{\text {th }}$ century until the Civil War in 1936. This study covers the professional and intellectual activity of the Salvi family, including the photo store Carlos Salvi Loscos founded and managed in 1887 and the magazine Instantáneas, created and directed by his brother Manuel Salvi Loscos in 1898. Hitherto unpublished data is provided on the history of Spanish photography along two main lines: on one hand, the social and cultural impact of the stores on photographic activity, and on the other, the purpose and importance of the magazine Instantáneas, among the publications specialising in the field, through the analysis of its contents.
\end{abstract}

$1 \quad$ Universidad Complutense de Madrid (España)

E-mail: jmvigil@ucm.es

2 Universidad Complutense de Madrid (España)

E-mail: molivera@ucm.es 
Keywords: Photography; History of Photography; Photography stores; Photography Industry; Carlos Salvi Loscos; Manuel Salvi Loscos; the Instantáneas magazine.

Sumario. 1. Introducción. 2. Las revistas de fotografía y los comercios fotográficos de entre siglos. 3. Los hermanos Salvi Loscos. 4. El establecimiento fotográfico de Carlos Salvi. 5. La revista Instantáneas de Manuel Salvi. 6. Conclusiones. 7. Referencias bibliográficas.

Cómo citar: Sánchez Vigil, JM, Olivera Zaldua M. (2017) El establecimiento fotográfico y la revista Instantáneas de los hermanos Salvi Loscos. Documentación sobre el comercio, la industria y los modelos comunicativos en fotografía, en Documentación de las Ciencias de la Información 40, 91-108.

\section{Introducción}

Los comercios de fotografía cumplieron una importante función sociocultural al constituirse en puntos de encuentro e intercambio de experiencias creativas y técnicas. Fueron además dinamizadores de la cultura al patrocinar publicaciones especializadas con información de referencia para los investigadores. Es objeto de este trabajo poner en valor el comercio, la industria y los modelos comunicativos en fotografía desde la actividad profesional e intelectual de la familia de empresarios Salvi, a través del establecimiento fotográfico fundado y dirigido por Carlos Salvi Loscos y de la revista Instantáneas, creada y dirigida por su hermano Manuel Salvi Loscos, con el objetivo de aportar nuevos datos a la historia de la fotografía española desde las perspectivas indicadas: comercial, industrial y comunicativa.

La metodología empleada ha sido cualitativa y cuantitativa. Se ha realizado la revisión bibliográfica sobre la industria de la fotografía y sobre las publicaciones periódicas especializadas en la materia, con el fin de contextualizar el establecimiento de Carlos Salvi en la época, e investigar su vinculación a instituciones y su función sociocultural. Se han elaborado dos bases de datos para el análisis de contenidos de Instantáneas y la recuperación de la información, una para los autores, secciones, artículos y fotógrafos, y otra para los autores y temas de las portadas.

La fotografía española adolece de estudios sobre la industria y la comercialización de materiales y productos, así como las empresas, fabricantes y establecimientos distribuidores, a excepción de Historia de la industria fotográfica española (Carrero de Dios, 2001). En lo que se refiere a los pequeños y medianos comercios se conocen los nombres de algunos propietarios de establecimientos (Salvi, Soldati, Escobar, Saénz Corona y Braulio López), pero poco o nada se sabe sobre su aportación a la fotografía.

Por lo que respecta a las revistas especializadas en el periodo que nos ocupa, es imprescindible La fotografia en España en el periodo de entreguerras 1914-1939 (Insenser, 2000), en el que se analizan la mayor parte de las publicaciones editadas en los años que se indican. Deben añadirse trabajos posteriores, caso de Avante (Sánchez Vigil, Olivera Zaldua, 2015) o Unión Fotográfica (Sánchez Vigil, 2016). Aunque las publicaciones especializadas quedan claramente delimitadas por su contenido, en fotografía nos encontramos con revistas que no siendo sobre la materia mantienen un vínculo desde otras perspectivas, caso de Instantáneas, surgida desde la industria y de contenido literario. 
Las fuentes principales para la obtención de datos sobre los hermanos Salvi Loscos han sido la Hemeroteca Digital del diario $A B C$ (www.abc.es), en la que se ha localizado importante información para elaborar sus biografías. Para las revistas de moda se ha consultado la Hemeroteca Digital de la Biblioteca Nacional de España (www.bne.es), así como los anuncios de prensa de varias publicaciones entre los años 1897 y 1915. La revista Instantáneas (146 números en total) ha sido consultada en la Biblioteca Digital de la Comunidad de Madrid (http://www.bibliotecavirtualmadrid.org, números 1-117), y Biblioteca Digital Memoria de Madrid (www.memoriademadrid.es, números 1- 81, 122-129, 131-136 y 140-146). Los 8 ejemplares no localizados en las bibliotecas públicas (números 118-121, 130 y 137-139) se han consultado en la colección particular del bibliófilo Rafael Díez Collar ${ }^{3}$.

\section{Las revistas de fotografía y los comercios fotográficos de entre siglos}

Las revistas de fotografía jugaron un papel fundamental como órganos de difusión de las asociaciones y sociedades de profesionales y amateurs, y fueron escaparate de la evolución tecnológica al presentar las novedades sobre cámaras, objetivos, negativos, papeles y accesorios. En el Anuario Fotográfico Hispano-Americano para 1890 se reseñaron 56 publicaciones especializadas, ninguna de ellas española, y entre ese año y 1900 salieron: Revista Fotográfica (Barcelona, 1891), Novedades Fotográficas (Bilbao, 1893), La Fotografía Práctica (Barcelona, 1893), y Arte Fotográfico (Sevilla, 1896). En la primera década del siglo XX se publicaron las siguientes: La Fotografia (1901), Photos (1902), Daguerre (1904), Avante (1905), Graphos Ilustrado (1906), Radium (1906) y el Boletín de la Sociedad Fotográfica de Madrid (1906) (Sánchez Vigil, 2013: 75).

La tipología de estas publicaciones responde a su función, en ocasiones de carácter general, con todo tipo de contenidos, y en otras con enfoque técnico como en el caso de los boletines de las empresas fabricantes o comerciales. Una de ellas fue Instantáneas, publicada a partir de octubre de 1898, y cuyo contenido superó el ámbito fotográfico al que hace clara referencia en su título y en las distintas secciones. Profusamente ilustrada, se proyectó hacia la literatura y el arte, ocupando el espacio que dejaban las dos más significativas del momento: Blanco y Negro (1891) y Nuevo Mundo (1894).

En cuanto a los establecimientos fotográficos, cumplían una misión distribuidora al vender material de fabricación nacional o importado, asumiendo el papel de intermediarios entre los fabricantes y los compradores, pero también una función didáctica puesto que en sus locales recibían los clientes las primeras clases para el manejo de los aparatos. A finales del siglo XIX el principal fabricante estadounidense del que se recibía material era Eastman-Kodak, y entre los europeos se encontraban Monckhoven, Guilleminot, Lumière, Jougla, Britania Works, y el grupo Ilford con tres marcas populares: Imperial Dry Plate, B. J. Edwards, y Marion and Co. (Carrero de Dios, 2001: 41).

\footnotetext{
${ }^{3}$ Agradecemos la colaboración de Rafael Díez Collar, en cuya biblioteca personal se conservan los ejemplares impresos de Instantáneas que no hemos localizado en centros públicos.
} 
El material (papeles, vidrios, líquidos, cámaras y accesorios) se distribuía al por mayor en los grandes establecimientos, y al por menor en las droguerías y tiendas diversas, incluidas las de ultramarinos. En la década de los ochenta los comercios proliferaron debido a la fabricación masiva de cámaras y de placas secas, así como de los complementos necesarios para la práctica de la foto. En este ambiente abrió Carlos Salvi su negocio en 1887, y junto a él destacarían a principios del siglo XX los siguientes: Graphos de Antonio Escobar (Madrid); Compañía General de Material Fotográfico de Torcida García y Cía., y Barandiarán y Cía. (Bilbao); Almacén Droguería San Antonio de los Hijos de Blas Cuesta (Valencia); Berrens y Soulé, Fernández y Carbonell, Riba, y Olaguer (Barcelona), la viuda de Tornero (San Sebastián), y José Solá i Soler (Girona).

\section{Los hermanos Salvi Loscos}

La familia de comerciantes Salvi fue muy popular en Madrid desde finales del siglo XIX hasta bien entrado el XX por su actividad vinculada a la moda, la fotografía y los instrumentos musicales. Además de su trabajo profesional llevaron a cabo una labor cultural que se relaciona con la prensa especializada al publicar las revistas Gran Moda, Moda y Arte, e Instantáneas. La primera fue presentada en enero de 1894, la segunda en enero de 1897, y la tercera salió semanalmente a partir de octubre de 1898.

El patriarca fue el italiano Manuel Salvi, casado con la zaragozana Manuela Loscos y propietario del comercio "El Sagrado Corazón. Casa Salvi", dedicado a la venta de ropa blanca para la casa y para las señoras, tal y como indicaban sus anuncios: "Puede usted adquirir las sedas que necesita en la Casa Salvi, Clavel 1, entresuelo. Apunte su petición, y no dude será atendida"4. El comercio participó en las Exposiciones de Industrias Madrileñas de finales del XIX, y fue un referente para las damas de la alta sociedad.

Manuel Salvi tuvo dos hijos: Manuel y Carlos Salvi Loscos, ambos con vocación artística, el primero por la pintura y el dibujo y el segundo por la fotografía. Manuel Salvi Loscos fue escritor, pintor, dibujante y litógrafo. En 1879 realizó las viñetas del Almanaque de la risa, y en 1880 se anunciaba en la prensa como especialista en heráldica como pintor artista ${ }^{5}$, con taller en el número 10 de la plaza del Príncipe Alfonso de Madrid. Diseñó bordados, estandartes, diplomas, portadas de partituras y carteles publicitarios de espectáculos y de empresas, entre ellos los de las máquinas de coser Singer en 1880, las fiestas taurinas de Pamplona, Palencia, Valladolid, Burgos, Vitoria y San Sebastián (1881-1885), o el del circo Price para la Compañía lírico-dramática de Guillermo Cereceda (1883).

\footnotetext{
4 La Última Moda, 15 de febrero de 1891. Anuncio publicitario.

${ }^{5}$ Anuario Almanaque de Comercio, de la Industria, de la Magistratura y de la Administración (1880-1885), editado por Bailly-Baillière, p. 412.
} 


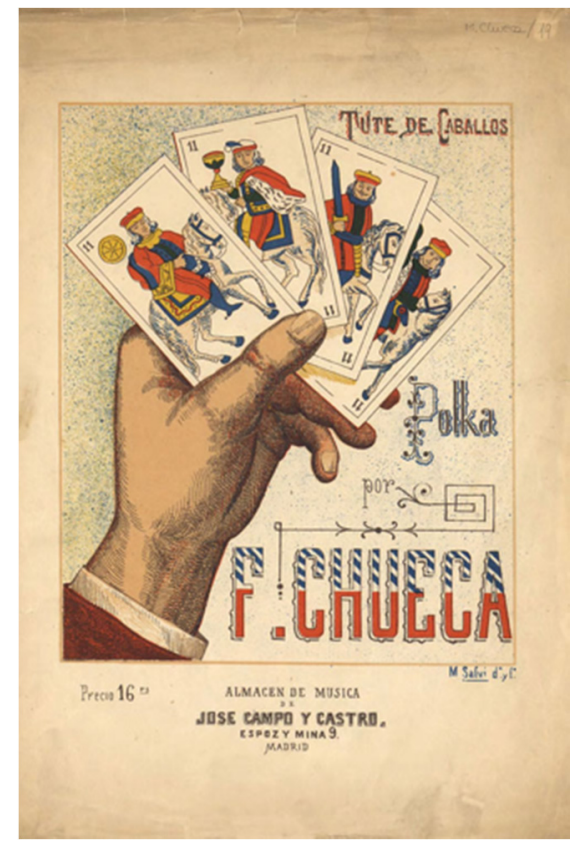

Fig. 1. Ilustración de Manuel Salvi.

Portada de la polca Tute de caballos del compositor Federico Chueca

En 1884 abrió estudio de dibujo y pintura en el número 53 de la calle Montera, y en la misma dirección creó la revista quincenal La Bordadora y el día de la moda, en la que además de figurines, dibujos y abecedarios (3.000 grabados al año) se ofrecía "una moral y amena parte literaria". A partir de entonces su firma fue habitual en diferentes revistas, como Los Toros (1886) o La Última Moda, en la que publicó entre 1889 y 1895: "Acompaña como regalo una hoja con cinco patrones y al dorso multitud de dibujos para bordados artísticos por D. Manuel Salvi",

En 1888 comenzó una serie de álbumes de dibujos para bordados que fueron distribuidos por el diario El Liberal, y que superaron los 150 números. Su popularidad fue tal que los lectores le encargaban diseños específicos para bordados a través de la sección de correspondencia. En 1890 viajó a París para inspirarse en las novedades de la moda francesa, y en marzo de 1894 fundó y dirigió Gran Moda, dedicada a la presentación y difusión de las creaciones parisinas. En enero de 1897 puso en marcha Moda y Arte, donde publicó numerosas ilustraciones sobre figurines, abecedarios y bordados. En octubre de 1898 presentó la revista Instantáneas para la que realizó varias portadas y en la que anunció sus obras en 1899: Labores empezadas para colegios, conventos, propia para regalos; Álbumes de abecedarios para bordar sábanas, almohadas, mantelerías, toallas y pañuelos; y Dibujos sobre papel y telas para bordar.

Otra actividad cultural de relevancia de Manuel Salvi fue la puesta en marcha de la Biblioteca de Literatura Contemporánea, de la que fue editor en 1901. Diseñó los bocetos para las fiestas de carnaval en Madrid de 1902, y el Ayuntamiento de 
Pamplona le encargó un diploma para regalar al compositor Pablo Sarasate con motivo de las fiestas de San Fermín?. En el Anuario de Comercio de 1903 se anunciaba como "Pintor heráldico y dibujante de bordados". El 4 de septiembre de 1904 el establecimiento de la calle Clavel sufrió un incendio, el local quedó completamente destrozado y Salvi perdió el conocimiento por efectos del humo: "Sólo se pudo salvar una caja de caudales donde guardaba alhajas y dinero, por cuyo salvamento mostraba gran interés" 8 .

El 30 de octubre de 1905 presentó la revista La mujer ilustrada y en diciembre de 1906 fue contratado como director artístico del establecimiento "El Encaje Madrileño", fundado por Manuel González. En 1908 fundó La moda práctica y abrió junto a varios socios, entre ellos el actor Emilio Carreras, el Salón Regio para proyecciones cinematográficas, del que fue director gerente ${ }^{9}$. Se dedicó también a montar espectáculos y patentó el "Salón encantado", donde exhibía vistas de la guerra de Melilla ${ }^{10}$. En esos años continuó publicando carpetas de dibujos, entre ellas: Enlaces y monogramas; Fantasías caligráficas para dibujantes, pintores y bordadoras, grabadores (obra en 4 álbumes, adoptada por colegios, institutos, escuelas normales, seminarios y academias de artes y oficios), y Gran Moda. Labores artísticas ${ }^{11}$. Otro de sus trabajos destacados fue el Álbum del año 1912: la mujer española y americana, reseñado por el diario $A B C^{12}$.

En 1912 obtuvo Medalla de Oro en el concurso internacional de dibujo de la sociedad Progreso del Arte de Florencia. Dos años después, el 21 de septiembre de 1914, publicó en El Globo el artículo "La antimaternidad" sobre el aborto en las clínicas clandestinas, y el 21 de enero de 1915 dedicó en el mismo diario un texto a México con el título "iQuien tuviera la enmienda!”. Todavía a comienzos de los años veinte mantenía abierto el negocio, trasladado del número 1 de la calle Clavel al 16 de Gravina, donde se anunciaba también como "Academia de Dibujo, Pintura decorativa, Carreras Oficios y Oposiciones femeninas". Allí publicó el álbum Novelty dedicado a bordados y a la ropa blanca ${ }^{13}$.

Los últimos años de su vida fueron intensos y difíciles. Fue atropellado en la plaza de Canalejas el 31 de enero de 1923, trató de reeditar sin éxito la revista Instantáneas $^{14}$ en junio de ese año y publicó el álbum Eva reina en junio de 1924. Ganó un concurso de arte decorativa religiosa en Turín en 1926 y publicó en diciembre de 1928 el artículo "El encaje. Su historia" en Heraldo de Madrid. Su situación económica fue precaria, y a través de la Unión de Empresas Periodísticas recibió varios donativos para sobrevivir. En La Correspondencia Militar del 29 de diciembre de 1928 se afirma: "El Sr. Salvi a sus setenta y tantos años se haya enfermo y desvalido". En 1929 realizó la cubierta del libro Los caballeros de Loyola de Rafael Pérez y Pérez, y los últimos datos sobre su persona los encontramos en el diario $\mathrm{La}$

\footnotetext{
${ }^{7}$ Blanco y Negro, 12 de julio de 1902.

${ }^{8}$ El Imparcial, 5 de septiembre de 1904.

${ }^{9}$ Revista Ilustrada de Banca, Ferrocarriles, Industria y Seguros, 25 de mayo de 1908.

${ }^{10}$ Anuario e Invenciones, 10 de julio de 1909.

${ }^{11}$ Estas carpetas no tienen fecha de publicación. Gran Moda. Labores artísticas se conserva en la Biblioteca Nacional de España, Sig. DL 2151209.

${ }^{12} A B C, 2$ de enero de 1912. Nota de prensa.

${ }^{13} A B C, 2$ de enero de 1920. Anuncio.

${ }^{14}$ La Libertad, 19 de junio de 1923.
} 
Nación el 4 de enero de 1932 tras romperse un fémur. Debió fallecer durante la guerra civil de 1936-1939.

Carlos Salvi Loscos (Zaragoza, 1857-Madrid, 1919) estudió música y se especializó en fotografía. En 1879 publicó un Método de acordeón, y a partir de 1880 se anunció como profesor de música en el Anuario Almanaque de Comercio, de la Industria, de la Magistratura y de la Administración, con estudio en el número 4 de la calle Tres Peces.

En 1887 abrió junto a Alfredo Mahou un negocio para la venta de productos, cámaras y objetos relacionados con la fotografía. Casó con Pascuala Lorente Goicoechea y en la explotación del comercio colaboró su hija Pilar. Su intensa labor al frente del negocio durante más de un cuarto de siglo le permitió mantener una estrecha relación con profesionales y amateurs. En junio de 1888 ya era popular en los círculos sociales, como prueba su participación en la Fiesta Libre del Pensamiento organizada por el Ateneo Familiar de Madrid en la villa de Pinto: "Amenizando el viaje con su música y tomando también varias vistas y grupos fotográficos" $" 15$.

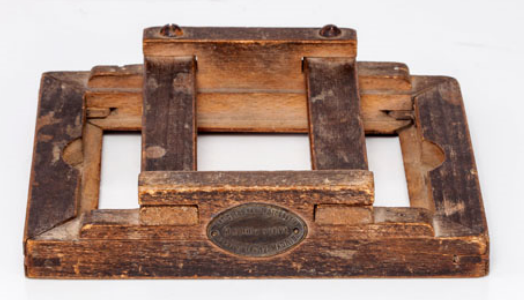

Fig. 2. Bastidor para contactos de la galería fotográfica Mahou y Silva

En la última década del siglo XIX formó parte del grupo de aficionados que creó la Sociedad Fotográfica de Madrid, y contribuyó a organizar el primer concurso de esta entidad financiando un premio para profesionales. Falleció en Madrid el 11 de marzo de 1919 en su domicilio del Paseo de Rosales 52-54 ${ }^{16}$. En la revista Unión Fotográfica se publicó la necrológica: "El día 11 de este mes falleció repentinamente el que fue conocidísimo industrial D. Carlos Salvi. ¿Qué fotógrafo profesional de España no habrá tenido relaciones comerciales con él? Hombre laborioso era, sin embargo, más conocido todavía entre los aficionados de la buena época. De aquella en que en su tienda de la calle Espoz y Mina se reunía la flor y nata de los más entusiastas, de los que hacían colección o poco menos de aparatos, y acostumbraban no acostarse sin haber tirado y revelado su docena diaria de plaquitas. ¡Descanse en paz el amigo don Carlos!"17.

\footnotetext{
${ }^{15}$ Los Dominicales del Libre Pensamiento, 3 de junio de 1888.

${ }^{16}$ Salvi y su esposa, que falleció el 7 de septiembre de 1933, fueron enterrados en la sepultura $n^{\circ} 22$ del Patio Santo Cristo de la Sacramental de San Lorenzo de Madrid.

${ }^{17}$ Unión Fotográfica, 15 de marzo de 1919, p. 7.
} 


\section{El establecimiento fotográfico de Carlos Salvi}

El desarrollo de la fotografía en lo que se refiere a la industrialización y por tanto a la creación de fábricas productoras de cámaras, objetivos, emulsiones, papeles, líquidos y accesorios, aumentó la necesidad de contratar almacenes y comercios distribuidores, encargados de surtir a profesionales y aficionados. Uno de ellos fue el de Carlos Salvi, cuyo interés por la fotografía le llevó a abrir en 1888 un establecimiento en el número 17 de la calle Espoz y Mina de Madrid ${ }^{18}$ con el nombre "Mahou y Salvi", en sociedad con el industrial cervecero Alfredo Mahou Solana, propietario de una galería de retratos ${ }^{19}$.

En 1888 publicaron el primer catálogo con una impresionante oferta de material ${ }^{20}$. Al negocio acudieron asiduamente profesionales y aficionados para comprar cámaras, placas, papeles y líquidos necesarios para el revelado y el positivado. Ello le permitió conocer a los intelectuales, científicos y aristócratas que tenían la fotografía como "sport" y a los que la empleaban como herramienta y medio para documentar sus actividades. En 1892 se publicó el Catálogo para Fotografía de Mahou y Salvi, impreso en el taller de los Sucesores de Rivadeneyra, y el 6 de octubre de ese año Salvi ya se anunció solo en la revista Monigotes: "Casa Salvi. Fotografía al alcance de todos. Máquinas instantáneas y aparatos completos para aficionados y artistas. Primera Casa en España. Catálogos Gratis. Espoz y Mina, 17”. En 1894 publicó otro catálogo con el título Artículos para fotografías, profusamente ilustrado, con un índice detallado de los materiales, y un gran surtido "en cámaras oscuras para galería de viaje, objetivos, obturadores, aparatos instantáneos completos para aficionados, placas, papeles, productos químicos, cristales, y accesorios para la fotominiatura". La cubierta modernista se basaba en la tipografía enmarcada en orla a modo de cenefa, probablemente diseñada por su hermano Manuel. Además de los artículos fotográficos comercializó también instrumentos musicales, fundamentalmente pianos, cuya venta compatibilizó con la fotografía.

\footnotetext{
${ }^{18}$ La solicitud de la licencia al Ayuntamiento lleva fecha del 25 de mayo de aquel año. Archivo de Villa de Madrid. Expediente 7-368 y 369-1.

${ }^{19}$ La familia de empresarios cerveceros Mahou tiene origen en el francés Casimiro Mahou, instalado en Madrid a mediados del siglo XIX, donde abrió una fábrica de papel pintado. Uno de sus hijos, Alfredo Mahou y Solana, aficionado a la fotografía, se estableció como profesional en 1870 en el número 29 de la calle Amaniel, donde abrió el estudio Almayso, cuyo título formó con las iniciales del nombre y apellidos. Dirigió la galería hasta 1913, fecha de su fallecimiento, y la mantuvo en activo hasta 1931 su sobrino Carlos Mahou.

${ }^{20}$ La Ilustración Española y Americana, 30 de junio de 1888.
} 


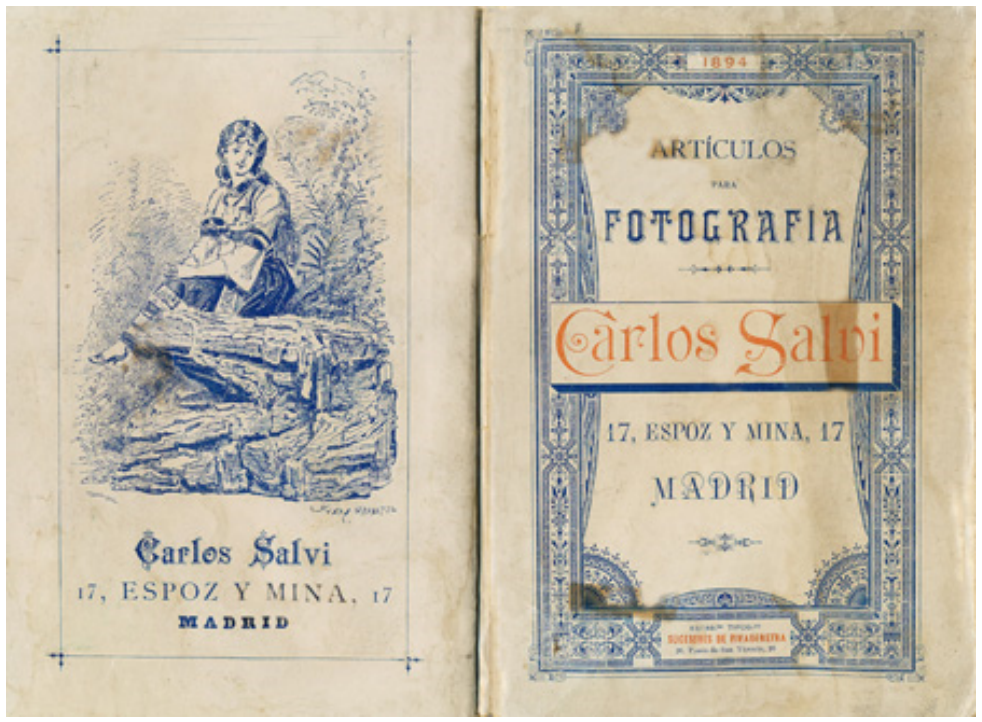

Fig. 3. Catálogo de artículos de fotografía de Carlos Salvi, 1894.

Biblioteca Nacional de España

En el comercio instaló laboratorio y galería, al objeto de que los clientes pudieran probar los aparatos y artículos. Además de las cámaras vendió los productos químicos de E. Merck (Darmstandt), las placas secas de G. Nys y Perron (París), y los objetivos de H. Warkinson Co. (Londres), J. H. Dallmeyer (Londres), Ross y Compañía (Londres), C. A. Steinheil Soerhne (Munich), Voigländer, Carl Zeiss (Jena), y J. F. Hermagis (París).

Los contactos personales hicieron del establecimiento un cenáculo donde se celebraron encuentros y tertulias, por otra parte comunes en las trastiendas de reboticas y droguerías donde se adquirían los químicos para hacer visible la imagen. Así conoció al entonces político Antonio Cánovas del Castillo Vallejo, que comenzó a practicar la foto como aficionado en 1897 influido por su hermano Máximo Cánovas y por Salvi, a quien compró una cámara Anschütz de 9x12 (Positiva, 1906: 102-109), y con quien haría sus primeros reportajes de edificios, plazas, escenas callejeras y populares (Cánovas, 1920: 6-8).

Durante 1897 y 1898 la trastienda del comercio fue el lugar de encuentro donde se gestó la Sociedad Fotográfica de Madrid, compuesta por los citados hermanos Cánovas del Castillo Vallejo, el conde de Agüera, el marqués del Riscal, Manuel Suárez Espada, José Ramón Melgarejo, Andrés Ripollés, José Macpherson, Telesforo Pérez Oliva, Baltasar Hernández Briz, y los generales Casimiro Bona y José Echagüe (Martín; Muñoz, 2004: 37).

El 15 de agosto de 1897 el diario La Época convocó un concurso de fotografías cuyo tema fue el entierro del presidente Antonio Cánovas del Castillo, asesinado el día 8 de ese mes en el balneario de Santa Águeda (Mondragón). Entre los premios se ofrecía la exposición de las imágenes ganadoras en el escaparate del comercio de Salvi. En 1899 formó parte del jurado de fotografía del Almanaque Bailly-Bailliére junto a Manuel Alviach y Fernando Debas, y editó otro catálogo que regaló con el libro Nuevo manual de fotografia práctica de R. Swift. Amplió por entonces el 
negocio para la venta de instrumentos musicales, especialmente pianos, y la falta de espacio obligó al grupo de la Sociedad Fotográfica a buscar otro lugar de reunión, trasladándose al Círculo de Bellas Artes donde fundaron la sección de Fotografía, que comenzó su actividad el 1 de febrero de 1899 (Cánovas, 1904).

El 1 de febrero de 1903 solicitó del Ayuntamiento licencia para el nuevo local de la calle Sevilla 12-14, dedicado a la venta de productos fotográficos y "música mecánica", decorado con pinturas modernistas por su hermano Manuel ${ }^{21}$. Los ingresos del negocio aumentaron en 1904, procedentes de dos vías concretas: la venta de cámaras portátiles de fácil manejo, y de los negativos y papeles empleados en los estudios y laboratorios.

Salvi no dejó de practicar la fotografía y continuó formando parte de la Sociedad Fotográfica de Madrid, según consta en la relación de socios que publicó la revista La Fotografía en febrero de 1904. En septiembre de ese año el fotógrafo y dibujante Carlos Iñigo le incluyó en la serie de caricaturas con las que ilustró la revista $L a$ Fotografia, representándolo sentado al piano sobre una banqueta a modo de cámara con trípode.

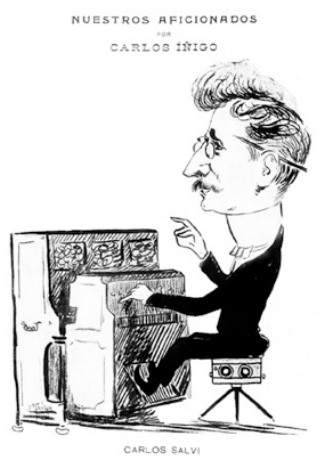

Fig. 4. Carlos Salvi. Caricatura por Carlos Iñigo

Revista La Fotografía, febrero de 1904

En el catálogo general que editó aquel año, con anuncio modernista del establecimiento firmado por K. Ansel de Dresde, ofertaba: "Especialidad en trabajos de laboratorio para aficionados. La casa se encarga de hacer estos trabajos en inmejorables condiciones, ampliando cualquier tamaño que desee". Por entonces, las empresas a las que representaba como agente eran: J. H. Dalmeyer, Ross \& $\mathrm{C}^{\mathrm{o}}$, Carl Zeiss, C. P. Goerz, Ilford Ltd., G. Nys, J. Carpentier, J. Richard, H. Warkinson Co, Demaría Frères, Talbot, Emil Busch, Eastman Kodak, Agfa, E. Wünsche, L. Gaumont \& Cie, A. Lumiére \& Fils, J. Haulf \& $C^{\circ}$, The Paget, Julius Blüthner, J. Herbert Marshall, M. Welte \& Sohne, y Wilcox \& White $\mathrm{C}^{\circ}$.

\footnotetext{
${ }^{21}$ Anuncio en El Globo, 30 de enero de 1903. La licencia de apertura se conserva en el Archivo de Villa, expediente 14-122-43.
} 
En 1905 organizó una exposición con motivo del viaje de Alfonso XIII a París, exhibiendo en el escaparate varios retratos del monarca y de Émile Loubet, presidente de Francia, tomados con una cámara Voigtländer ${ }^{22}$. En 1907 los tres grandes establecimientos de comercio de productos fotográficos en Madrid eran Escobar (Victoria, 2), Marciano (Fuencarral, 5) y Salvi (Sevilla, 14), que modernizó sus instalaciones para acoplar más pianos, especialmente el modelo clásico Ángelus y el eléctrico Welte ${ }^{23}$. En 1914 se abrieron otros dos negocios de relevancia: Kodak (Puerta del Sol, 8) y Aramburo (Príncipe, 12). La prensa destacó la incorporación de una caja registradora al comercio de Salvi: “ ${ }_{i} H$ Hermoso espectáculo!! En uno de los más acreditados y elegantes establecimientos de Madrid, el almacén de aparatos fotográficos de D. Carlos Salvi, Sevilla 12, acabamos de ver una magnífica registradora National eléctrica (Preciados, 11) dedicada a la administración del negocio al detall de tan importante casa. Felicitamos al Sr. Salvi, quien ha patentizado su amor al progreso y al buen orden"24. Poco antes de fallecer, en agosto de 1918, el negocio fue adquirido por dos socios: Lirón Gordo y González, que se anunciaron como Sucesores de Salvi hasta la guerra civil de 1936.

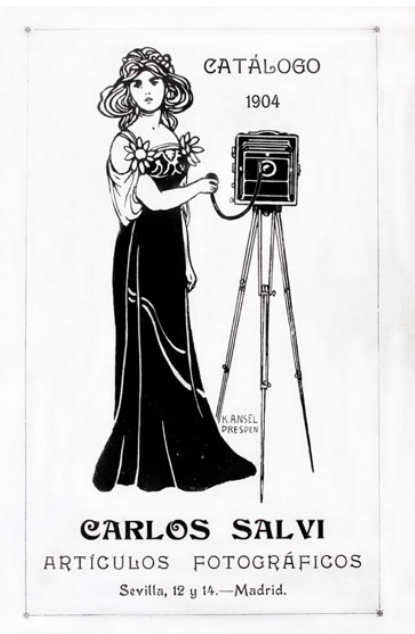

Fig. 5. Ilustración del catálogo de Carlos Salvi, 1904

\section{La revista Instantáneas de Manuel Salvi}

La revista Instantáneas fue creada por Manuel Salvi en octubre de 1898 como publicación ilustrada, con dos contenidos claramente diferenciados pero complementarios: literatura y fotografía. Salió en tres etapas con subtítulos diferentes; en la primera (octubre de 1898 a diciembre de 1900, números 1-117) se denominó

\footnotetext{
${ }^{22}$ El País, 6 de junio de 1905.

${ }^{23} A B C, 4$ de abril de 1912.

${ }^{24}$ La Correspondencia de España, 12 de septiembre de 1914.
} 
"Revista Semanal de Artes y Letras", en la segunda (enero a marzo de 1901, números 118-127) "La vida ilustrada. Semanario de Actualidad de literatura clásica, humorística y artística", y en la tercera (15 de marzo a diciembre de 1901, números 128-146) cambió a "Gran Moda. Revista Hispano-Portuguesa-Americana". Se realizaron varios números extraordinarios dedicados a Sevilla (marzo de 1899), Zaragoza (octubre de 1899), Carnaval (febrero de 1900) y Valencia (julio de 1900).

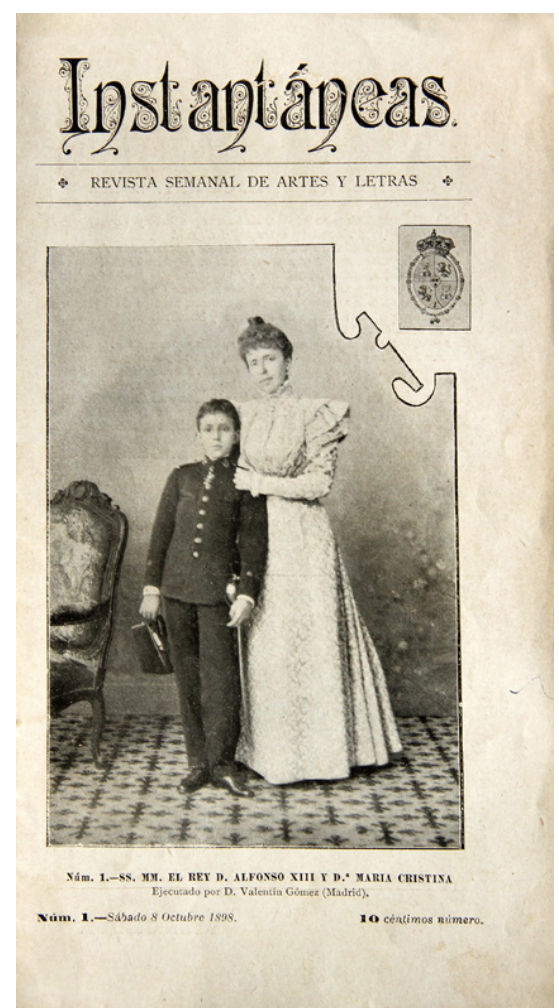

Fig. 6. Primer número de Instantáneas, 1 de octubre de 1898

La sede estuvo en el negocio de Manuel Salvi, número 1 de la calle Clavel, y se imprimió en blanco y negro en el taller de Hijos de M. G. Hernández, situado en el 16 de la calle Libertad. El formato, de corte original, fue de $20 \times 10 \mathrm{~cm}$, con una media de 16 páginas en buen papel según la publicidad: "La única publicación española estampada en papel couché y a todo lujo".

El diseño interior respondía a los modelos de la época, ciertamente cuidado y con reproducciones de calidad en los grabados. Desde el número 14 las portadas fueron en color, y a partir del número 22 (28 de febrero de 1899) el cuché quedó solo para las cubiertas, que se ilustraron con retratos de reyes, políticos, artistas y personajes populares.

En su pretensión por aunar literatura y fotografía, Salvi solicitó la colaboración de escritores y periodistas de prestigio. Una forma de conseguirlo fue mediante el regalo de fotos realizadas por él mismo, y así lo hizo con Jacinto Benavente, a quien 
envió la imagen de un tren. El dramaturgo aceptó el encargo del artículo pero lo derivó a Gregorio Martínez Sierra, si bien finalmente se publicó con la firma de Benavente (Martínez Sierra, 2000: 95). Manuel Salvi escribió para el número 3 de 22 de octubre de 1898 un breve cuento que tituló "Cámara oscura", de contenido amoroso.

Los escritores habituales fueron: Juan Pérez de Zúñiga, José María Solís, Alejandro Larrubiera, Sinesio Delgado, Luis Álvarez González, Manuel Marzal Mestre y Gregorio Martínez Sierra, uno de los más activos durante 1899, con la sección "Placas" dedicada a la crónica cultural, las novedades editoriales y a los espectáculos. Se reservó una página específica a las viñetas humoristas en los que colaboraron dibujantes de prestigio como Ramón Cilla, José Román, Manuel Moral y Manuel Tovar. En las últimas páginas se insertó la publicidad, siempre con un espacio reservado al establecimiento de material fotográfico de Carlos Salvi (Espoz y Mina, 17). La media de anuncios fue de diez, generalmente en formato reducido, salvo excepciones, y de temática diversa: publicaciones, vestuario, alimentación, industria, perfumería y servicios (Tabla 1). A partir del número 12 descendió considerablemente, pasando de una docena a solo seis anuncios que se mantuvieron hasta la desaparición de la revista. Otros anunciantes en los últimos dos años del siglo XIX fueron: Benigno Ayora (Almacén de papel, calle Concepción Jerónima, 17), Venancio Vázquez (Ultramarinos, en Cuatro Calles) y la Compañía Dental Española (Cedaceros, 4).

TABLA 1. ANUNCIOS EN EL PRIMER NÚMERO DE INSTANTANEAS $(7 / 10 / 1898)$

\begin{tabular}{|c|c|c|c|}
\hline EMPRESA & PRODUCTOS & SECTOR & DIRECCIÓN \\
\hline $\begin{array}{c}\text { Compañía } \\
\text { Colonial }\end{array}$ & Chocolates y Café & Alimentación & Mayor, 18-20 \\
\hline La Soledad & Funeraria & Servicios & $\begin{array}{c}\text { Desengaño, } \\
10\end{array}$ \\
\hline Moda y Arte & Revista & Publicaciones & Clavel, 1 \\
\hline Rivas y Sanz & Camisas & Vestuario & Príncipe. 11 \\
\hline Salvi, Carlos & Fotografia, Pianos & Industria & $\begin{array}{c}\text { Espoz y Mina, } \\
17\end{array}$ \\
\hline $\begin{array}{c}\text { Sánchez } \\
\text { Ocaña }\end{array}$ & Perfumes & Perfumeria & Atocha, 35 \\
\hline Vilasante & Optica & Industria & Príncipe, 10 \\
\hline Zurro & Guantes & Vestuario & Carretas, 14 \\
\hline
\end{tabular}

\subsection{Las fotografías de Instantáneas}

En lo que respecta a la fotografía, aunque no se trató de una publicación específica sobre la materia, las imágenes se encuadran en el conjunto de revistas ilustradas con valor documental y artístico, presentadas en muchas ocasiones sin más texto que el pie explicativo. El interés por la foto se justifica, además de por el título, con la nota publicada en todos sus números, en la que se solicitaba la colaboración de los lectores para que enviaran imágenes al objeto de ser reproducidas: "Instantáneas hace un llamamiento a la colaboración fotográfica de todos sus lectores, fotógrafos y 
aficionados, rogándoles dirijan a sus oficinas todas las fotografías que puedan ser autorizadas para su reproducción, prefiriendo siempre sean de actualidad y de asuntos de interés general, tipos, costumbres, medios de transporte, trajes, monumentos, retratos de mujeres y hombres célebres, vistas, obras de arte, etc. etc.".

El uso del término "instantánea" en el título responde a su modernidad, en un momento en el que la fotografía de prensa estaba en pleno auge, con las primeras aplicaciones en las revistas, y ello sin perder la función documental desde su origen: "Con la instantánea nada pasa inadvertido, todo se puede reproducir y conservar, y gracias a ella también se pueden popularizar las maravillas que se guardan en los museos, en los palacios, en las catedrales, en sitios donde solo pueden gozar con su contemplación unos cuantos privilegiados" (Kasabal, 1898: 3).

La mayoría de las secciones llevaron como título temas fotográficos: "Positivas y Negativas", "Baño de viraje", "Diafragma Iris", "Placas", "Fuera de foco", "A través del objetivo", "Clichés", "Obturador", o la específica "Correspondencia Fotográfica", dedicada a comentar aspectos técnicos.

En cuanto a los fotógrafos, las firmas de profesionales y amateurs son numerosas, destacando: J. Almagro, R. Almela, Luis Álvarez González, J. H. D'Araujo, Damián Arbulo, Ricardo Argente (La Habana), G. Borke, Pablo Duomarco, J. Echagüe, Antoni Esplugas Valentín Gómez, Baltasar Hernández Briz, César Huerta, Mario Leitao (Lisboa), José Melgarejo, Méndez y Cao, Oraw-Raff, Pascual Rey, Javier Sánchez Manterola, Max Vascano (Máximo Cánovas del Castillo), F. Villegas y Charles H. Younger.

La puesta en página de las fotografías en los primeros números responde al siguiente modelo: grandes formatos para las verticales, media página para las horizontales y doble página para las imágenes en los centros de pliego. La media fue de 10 fotografías por número, con los pies numerados en inicio hasta enero de 1899, indicando en todos los casos la autoría. En los 12 primeros números se publicaron 120 fotos y una docena de viñetas humorísticas. La impresión en blanco y negro responde a la calidad media del resto de revistas de la época.

Por lo que respecta a la temática, la variedad fue absoluta: arquitectura, paisajes rurales y urbanos, retratos, tauromaquia, deportes, y sobre todo las composiciones pictorialistas de los amateurs, que aportaban una visión creativa. Entre las firmas destacaron las del doctor Baltasar Hernández Briz, miembro de la Real Academia de Medicina y de la Real Sociedad Fotográfica de Madrid, con excelentes tomas de monumentos, y la de Luis Álvarez dedicado a temas militares. En ocasiones se realizaron monográficos ilustrados por profesionales expertos en el tema, como el dedicado a la Semana Santa de Murcia con fotos de Almagro (25 de marzo de 1899).

Las ilustraciones aumentaron durante el primer semestre de 1900 en cada número, si bien proporcionalmente descendieron al pasar las páginas de 12 a 18 . El formato se mantuvo, con mayor tamaño en los centros de pliego. Este proceso se reinvirtió en la segunda mitad del año al reducir las páginas a ocho y en consecuencia las ilustraciones a media docena. Sin embargo, se mejoró la maqueta, enmarcando las fotos en orlas y líneas, y los fotograbados ganaron en detalle.

En la segunda etapa, a partir de enero de 1901 y con el subtítulo "la vida ilustrada" las páginas fueron 12 , con ocho ilustraciones de media de menor tamaño y peor 
impresión, y desde el número 127 (marzo de 1901) en que se dedicó en exclusiva a la moda las fotos fueron sustituidas por dibujos de línea.

\subsection{Las ilustraciones de portada}

Las portadas de Instantáneas se ilustraron en su mayoría con retratos fotográficos reproducidos a página, completados con dibujos realizados por el propio Manuel Salvi. La primera portada fue dedicada al rey Alfonso XIII junto a su madre María Cristina de Borbón, retratados en el estudio de Valentín Gómez (fig. 6), y la primera en color (alegoría de la fotografía) se publicó en el almanaque de diciembre de 1898, número 13 (fig. 8). Tan solo en los primeros 38 números se indicaron los autores de los retratos, entre los que se encontraban prestigiosos galeristas como Méndez y Cao (6), Valentín Gómez (4), Edgard y Fernando Debas (3), Miguel Huerta (2), Manuel Alviach (2), Audouard (1), Lokner (1) o Borke (1), pero la norma dejó de respetarse a partir de junio de 1899 hasta prácticamente la desaparición de la revista. En los últimos números, desde enero a marzo de 1901, y no de manera continua, volvieron a incluirse los autores de las portadas. En la primera y segunda etapa, correspondientes a 1898-1900, el protagonismo fue para la fotografía, y en la tercera, cuando la revista pasó a dedicarse casi exclusivamente a la moda, las fotos cedieron espacio a los dibujos, con representaciones costumbritas, estereotipos y tópicos. Por lo que respecta al contenido específico, el conjunto de fotografías constituye una interesante colección de retratos donde destacan las mujeres y específicamente las actrices, entre ellas las prestigiosas María Guerrero, Carmen Cobeña, Carmen Hidalgo o Rosario Pino (Tabla 2).

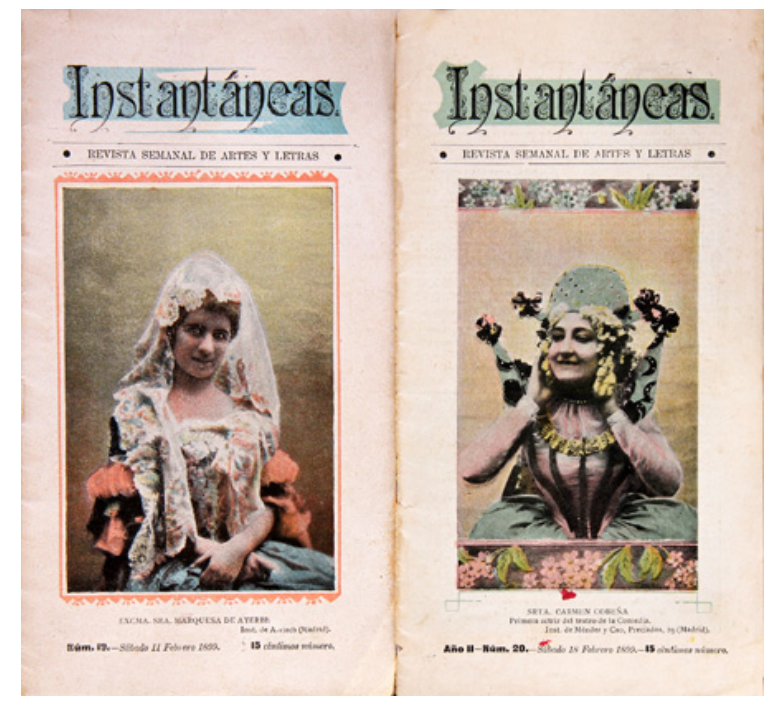

Fig. 7. Portadas de los números 19 y 20 de Instantáneas, 11 y 18 de febrero de 1899 
TABLA 2. PORTADAS DE INSTANTANEAS CON FOTOGRAFIAS FIRMADAS

\begin{tabular}{|l|l|l|l|}
\hline $\mathrm{N}^{\circ}$ & \multicolumn{1}{|c|}{ FECHA } & & \multicolumn{1}{|c|}{ AUTOR } \\
\hline 1 & $1898 / 10 / 08$ & Alfonso XIII y María Cristina de Borbón & Gómez, Valentín \\
\hline 2 & $1898 / 10 / 15$ & Polavieja, Camilo & Debas, Vda. Edgard \\
\hline 3 & $1898 / 10 / 22$ & Arguelles Bernaldo de Quirós, María & Gómez, Valentín \\
\hline 4 & $1898 / 10 / 29$ & Sancha, Ciriaco H. & Gómez, Valentín \\
\hline 5 & $1898 / 11 / 05$ & Mazzantini, Luis & Gómez, Valentín \\
\hline 6 & $1898 / 11 / 12$ & Ortega, Carmen & Méndez y Cao \\
\hline 7 & $1898 / 11 / 19$ & López Silva, José & Audouard \\
\hline 8 & $1898 / 11 / 26$ & Amanzana Barrera, María & Borke, G. \\
\hline 9 & $1898 / 12 / 03$ & Simonetti, Lorenzo & Méndez y Cao \\
\hline 12 & $1898 / 12 / 24$ & Hidalgo, Carmen & Estudio Fotográfico \\
\hline 13 & $1899 / 01 / 01$ & Alegoría de la Fotografia & Méndez y Cao. \\
\hline 14 & $1899 / 01 / 07$ & Isabel de Borbón & Debas, Edgard \\
\hline 15 & $1899 / 01 / 14$ & Carlos de Portugal & Bobone, A. (Lisboa) \\
\hline 16 & $1899 / 01 / 21$ & Bolado, Consuelo de & Alviach, Manuel \\
\hline 17 & $1899 / 01 / 28$ & Picón, Jacinto Octavio & Lokner \\
\hline 18 & $1899 / 02 / 04$ & "Olé Sevilla” (Pintura) & Méndez y Cao. \\
\hline 19 & $1899 / 02 / 11$ & Ayerbe, Marquesa de & Alviach, Manuel \\
\hline 20 & $1899 / 02 / 18$ & Cobeña, Carmen & Méndez y Cao \\
\hline 21 & $1899 / 02 / 25$ & Soler, Miguel & Méndez y Cao \\
\hline 22 & $1899 / 03 / 04$ & Bouguereau, W. (Pintura) & Goupil (París) \\
\hline 23 & $1899 / 03 / 11$ & Blasco, Señorita & Méndez y Cao \\
\hline 24 & $1899 / 03 / 18$ & Aza, Vital & Fotografia Moderna \\
\hline 25 & $1899 / 03 / 25$ & Pino, Rosario & Estudio Fotográfico \\
\hline 28 & $1899 / 04 / 25$ & Lerma, Matilde de & Debas, Fernando \\
\hline 30 & $1899 / 04 / 29$ & Gardeta, Fidela & Fotografia Artística \\
\hline 32 & $1899 / 05 / 13$ & Salvany, Hortensia & Huerta \\
\hline 33 & $1899 / 05 / 20$ & Ascanio, Josefina & Huerta \\
\hline 37 & $1899 / 06 / 17$ & Polo (Deporte) & Vascano, Máximo \\
\hline 38 & $1899 / 06 / 24$ & Montes, Francisca S. & Cubela, J. \\
\hline 51 & $1899 / 09 / 23$ & Loño, Dolores & Amador \\
\hline 122 & $1901 / 02 / 01$ & Guerrero, Maria; Diaz de Mendoza & García (Valencia) \\
\hline 123 & $1901 / 02 / 08$ & Domingo, Carmen & Tellez y Cía. \\
\hline 124 & $1901 / 02 / 15$ & Carnaval & Gorin y Salvi \\
\hline 125 & $1901 / 02 / 22$ & Guerrero, Maria & García (Valencia) \\
\hline
\end{tabular}

\section{Conclusiones}

El estudio de la documentación relacionada con la industria y el comercio de la fotografía es una asignatura pendiente, así como la investigación sobre la vida y obra de quienes fundaron y dirigieron este tipo de empresas. Las aportaciones sobre estas materias son fundamentales para entender la historia de la fotografía en su conjunto, ya que los establecimientos cumplieron una función social al ser punto de encuentro de profesionales y aficionados.

Sobre los hermanos Salvi indicaremos que se trata de empresarios modelo que emplearon sus establecimientos como centros dinamizadores, en especial el comercio de fotografía de la calle Espoz y Mina, en el que se organizaron encuentros de aficionados y profesionales, exposiciones y tertulias. Justifica esta conclusión el que a finales del siglo XIX se creara en dicho local la Sociedad Fotográfica de Madrid. En este sentido hemos de señalar que se propició el debate y el intercambio de experiencias y conocimientos.

En cuanto a la revista Instantáneas consideramos que es un referente para el estudio de la prensa ilustrada en el periodo de entre siglos, tanto por su calidad como 
por la cantidad de artículos e ilustraciones. Del análisis de los contenidos se concluye en primer lugar que Manuel Salvi realizó una excepcional función como editor y director, y que la publicación fue difusora del arte y la cultura con una visión original vinculando la fotografía a los contenidos. En ella publicaron prestigiosos escritores, periodistas, dibujantes y fotógrafos como se ha justificado.

Otra conclusión significativa se refiere a su especial formato, absolutamente creativo y fuera de norma en su contexto $(20 \times 10 \mathrm{~cm})$, en un momento en el que las grandes publicaciones seguían los modelos europeos prefijados. Se ha constatado que se publicaron 146 números entre octubre de 1898 y marzo de 1901, de los que se conservan 138 en bibliotecas públicas. Vistos los resultados incidimos en la cantidad y calidad de las imágenes, en especial de los retratos.

Por último, se aportan nuevos datos para la historia de la fotografía española en lo que se refiere al comercio, la industria y las publicaciones, poniendo en valor el papel de los establecimientos comerciales respecto al desarrollo técnico, así como al conocimiento de los materiales y los productos fabricados en España y en el extranjero.

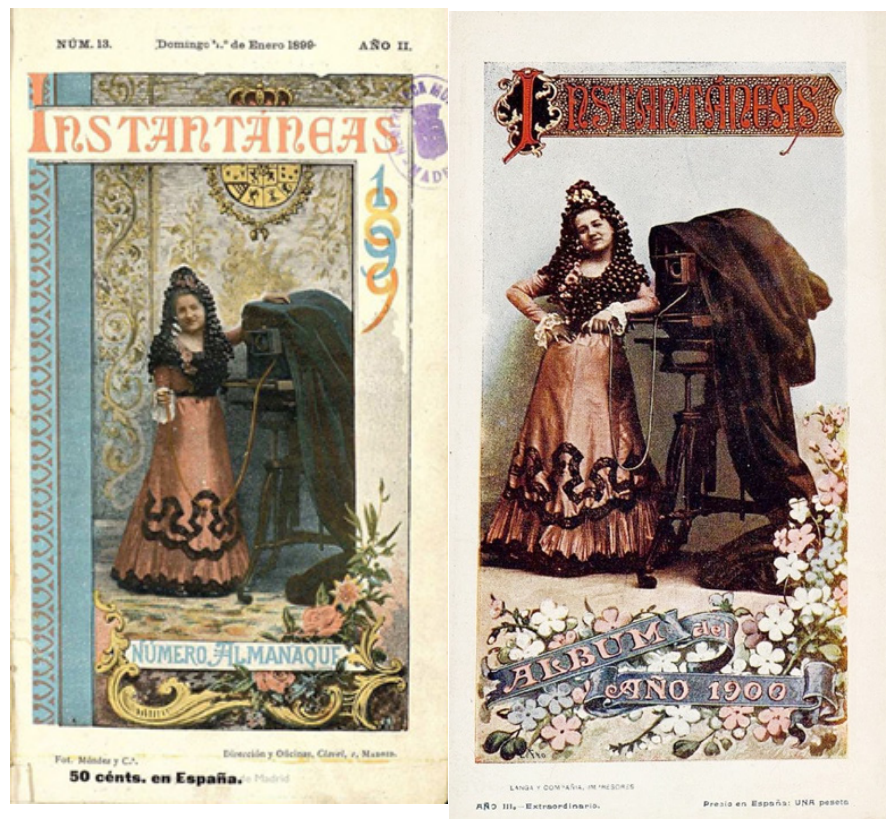

Figs. 8-9. Alegorías de la Fotografía.

Portadas de los álbumes para 1899 y 1900 


\section{Bibliografía}

Alcántara, Francisco (1906). "Industrias artísticas. El encaje madrileño por Manuel Salvi”, en El Imparcial, 10 de diciembre de 1906.

Cánovas, Antonio (1920). "Del origen de la Real Sociedad Fotográfica", en Unión fotográfica, $\mathrm{n}^{\mathrm{o}} 16, \mathrm{pp} .7-8$.

-(1904). "La crisis de la afición”, La Fotografía, diciembre, pp. 65-67.

Carrero de Dios, Manuel (2001). Historia de la industria fotográfica española. Girona: Centre de Recerca i Difusió de la Imatge.

Insenser, Elisabet (2000). La fotografía en España en el periodo de entreguerras (19141939). Girona: Centre de Recerca i Difusió de la Imatge.

Kasabal (1898). “Instantáneas”, en Instantáneas, 8 de octubre, pp. 3-4.

Manrique Núñez, Darío (2014). “Almayso, un Facebook del XIX”, en El País, 24 de agosto. http://ccaa.elpais.com [Consulta: 14/7/2016].

Martín López, Ana María; Muñoz García, Manuel (2004). Historia de la Real Sociedad Fotográfica: voluntad de fotógrafos. Segovia: Real Sociedad Fotográfica, Univ. SEK.

Martínez Sierra, María (2000). Gregorio y yo. Madrid: Pre-Textos.

Pando Despierto, Juan (1986) "Historia de la fotografía en Madrid", en Historia de la Fotografía Española. Actas del I Congreso de Historia de la Fotografía Española. Sevilla: Sociedad de Historia de la Fotografía Española, pp. 215-248.

Positiva (1906). "Dálton Kâulak", en Graphos Ilustrado, abril, pp. 102-106

Rafols, J. F. (1980). Diccionario de Artistas de Cataluña, Baleares y Valencia. Barcelona: Edicions Catalanes.

Salvi, Carlos (1894). Artículos para fotografia. Catálogo de la Casa Salvi. Madrid: Sucesores de Rivadeneyra.

Salvi, Manuel (1915). “México ¡Quien tuviera la enmienda!”, en El Globo, 21 de enero, p. 2.

-(1914). “La antimaternidad", en El Globo, 21 de septiembre, p. 2.

-(1910 ca.). Enlaces y monogramas. Album 1, 56 láminas. Madrid: Biosca impresor

-(s. f.). Fantasías caligráficas, para dibujantes, pintores y bordadoras, grabadores; obra en 4 álbum, adoptada por colegios, institutos, escuelas normales, seminarios y academias de artes y oficios. Madrid: Escuela de Dibujo y Pintura.

-(s. f.). Gran Moda. Labores artísticas. Madrid: Imprenta de Eusebio Fernández.

Sánchez Vigil, Juan Miguel (2016). “Análisis de la revista Unión Fotográfica, órgano de difusión de los empresarios del sector y referente en la materia (1919-1924)", en Anales de Documentación, v. 19, 2. En línea: http://dx.doi.org/10.6018/analesdoc. 19.2.251951. -(2013). La fotografia en España. Otra vuelta de tuerca. Gijón: Trea.

-(2000). La fotografía en España. Summa Artis XLVII, Madrid: Espasa.

Sánchez Vigil, Juan Miguel; Olivera Zaldua, María (2015). “Análisis documental de Avante, Revista de la Sociedad General de Fotógrafos de España (1905-1906)", en Anales de documentación, vol.18, $\mathrm{n}^{\mathrm{o}}$ 1. En línea: http://revistas.um.es/ analesdoc/article/ 209681/173551. 